\title{
PROBLEMS OF DESIGNING GEOPORTAL INTERFACES
}

\author{
Stanislav A. YAMASHKIN \\ National Research Ogarev Mordovia State University, Faculty of Geography \\ (68 Bolshevistskaya St., Saransk 430005, Russia), e-mail: yamashkinsa@mail.ru
}

\section{Milan M. RADOVANOVIĆ}

Geographical Institute "Jovan Cvijić", Serbian Academy of Sciences and Arts (9 Djure Jakšića St., Belgrade 11000, Serbia); South Ural State University, Institute of Sports, Tourism and Service (76 Lenin Ave., Chelyabinsk 45408o, Russia), e-mail: m.radovanovic@gi.sanu.ac.rs

\section{Anatoliy A. YAMASHKIN}

National Research Ogarev Mordovia State University, Faculty of Geography (68 Bolshevistskaya St., Saransk 430005, Russia), e-mail: yamashkin56@mail.ru

\author{
Alexander N. BARMIN \\ Astrakhan State University, Faculty of Geology and Geography \\ (20a Tatischev St., Astrakhan 414056, Russia), e-mail: abarmin6o@mail.ru \\ Viktor V. ZANOZIN \\ Astrakhan State University, Faculty of Geology and Geography \\ (20a Tatischev St., Astrakhan 414056, Russia), e-mail: victorzan44gmail.com

\section{Marko D. PETROVIĆ ${ }^{*}$} \\ Geographical Institute "Jovan Cvijićc", Serbian Academy of Sciences and Arts (9 Djure Jakšića \\ St., Belgrade 1100o, Serbia); South Ural State University, Institute of Sports, Tourism and Service \\ (76 Lenin Ave., Chelyabinsk 45408o, Russia), e-mail: m.petrovic@gi.sanu.ac.rs
}

Citation: Yamashkin, S.A., Radovanović, M.M., Yamashkin, A.A., Barmin, N.N., Zanozin, V.V., Petrović, M.D. (2019). PROBLEMS OF DESIGNING GEOPORTAL INTERFACES. GeoJournal of Tourism and Geosites, 24(1), 88-101. https://doi.org/10.30892/gtg.24108-345

\begin{abstract}
The manuscript is devoted to analysis of the problem of designing graphical geoportal interfaces. The support points for the problem solutions are formulated and rationale of each of them is given. The emphasis was placed on the following orientations: to a flexible process of interface development, the need to introduce adaptability, progressive development, the motivated abandonment of geospatial content management systems and the use of third-party libraries where necessary, problem-solving and achieving goals. The lists of basic functional and qualitative requirements for graphical geoportal interfaces are given. In the last segment, the authors share their experience in the development of geoportal solutions.
\end{abstract}

Key words: Geoinformatics, Geosciences, Design, Web-based GIS, Mordovia

\footnotetext{
* Corresponding author
} 


\section{INTRODUCTION}

In the conditions of active economic and information development of regions, the effective use and development of geographic information systems (GIS), in particular webbased GIS (geoportals), is becoming particularly relevant. This class of software systems providing access to information resources about the natural and socio-economic sites in different regions of the country contributes to the formation of an information environment that determines the sustainable development of society: from the economy and realization of political potential to the progress in social and cultural sphere (Koshkarev et al., 2008). Geoportals are used in various professional fields: tourism (Sigala, 2012), dissemination of information on geological and cultural heritage (Koszewski et al., 2018), formation of spatial data infrastructure (Denzer et al., 2015), information management in land use systems (Cegielska et al., 2018), decision support systems (Karabegovic \& Ponjavic, 2012), monitoring of technogenic systems (Xu et al., 2015), rational use of land and resources (Granell Canut et al., 2017; Reddy et al., 2018), analysis of the geoecological state of territories (Gachenko et al., 2016), emergency prevention and disaster reduction (Giuliani \& Peduzzi, 2011), traffic flow management and road traffic management (Gunay et al., 2014), integration of complex scientific studies and visualization of their results (Yakubaylik et al., 2014; Blake et al., 2017a) and so on.

Large cartographic services, such as Google Maps, OpenStreetMap, Microsoft Bing Maps, Yandex Maps and 2GIS take special places. They are not profiled on the provision of specialized environmental data for scientific analysis, but they provide a convenient interface for finding interesting objects by key requests, the quality and high-speed response of which is worth orienting to. In this context, it is worth mentioning the use of the crowdsourcing concept, the essence of which is to transfer the function of updating geographic data to anyone who wishes, i.e. to the entire world community .

This concept was implemented in OpenStreetMap in its pure form thanks to which their maps are very detailed, and any change in geographic features and infrastructure can be timely added to the cartographic database which provides unprecedented relevance of the data presented in the system. When creating geoportal systems, many problems are solved both from the field of software engineering and other applied disciplines: software complexes of this kind acquire maximum efficiency when solving the problem of obtaining and storing information and knowledge (Samakovlija \& Bartoli, 2017), automated analysis of collected data (Yermolaev et al., 2018; Yamashkin, 2018a; Yamashkin, 2018b), visualization of results and achievement of the possibility of working with them on the basis of modern web technologies (Fiedukowicz et al., 2012; Mehdi et al., 2014; Zhu et al., 2015). A special case is the navigation within a user-oriented geoportal and the search for geoinformation in large data sets. To solve this problem, advisory systems have been developed (Lombardo et al., 2015; Dareshiri et al., 2017).

\section{LITERATURE BACKGROUND}

\section{The history of designing geoportal interfaces}

Currently, a number of successful geoportal solutions that show their social and scientific significance have been proposed. In the mid-9o's of the last century, spatial data infrastructure (SDI) developed as new spatial data resource management mechanisms. In accordance with the Inspire Directive (2007), the Member States of the European Union (EU) should provide their spatial geographical data in a single standardized format. In addition, many countries realized the prospects of spatial data infrastructure and the value of spatial data for economic benefits. The aim of the directive is to create a single spatial data base for storing, processing, transferring and 
receiving these data within the EU to facilitate interaction with geographic information in solving political, social and economic issues. The adoption of the directive and the steps towards its implementation meant the universal recognition of SDI as the main path for further successful geoinformatic development (Koshkarev et al., 2008), and users witnessed the growing development of web-oriented web sites based on maps at national, regional and local levels for the professional use of geodata.

Spatial data on the INSPIRE geoportal are presented for all countries of the EU, and at the same time, many countries have their own national geoportals, for example: Sweden (http://www.geodata.se), Serbia (http://www.geosrbija.rs), Switzerland (http://geo.admin.ch), France (http://www.geoportail.gouv.fr), Poland (http://geoportal. gov.pl), the Netherlands http://www.nationaalgeoregister.nl), Germany (https://www. geoportal.de/), Finland (https://www.maanmittauslaitos.fi/) etc.

The US geoplatform (http://www.geoplatform.gov/) is also characterized by the availability of complete and integrated environmental and geographic information with an authentic concept of representing maps. Russia has also a number of geoportal solutions: when creating a geoportal of the spatial data infrastructure of the Russian Federation (http://nsdi.ru), the experience of the all-European initiative (INSPIRE) was taken into account, and Roscosmos geoportal (http://geoportal.ntsomz.ru) was created to solve the problem of cataloging Russian satellite data and it operates on the basis of the Research Center for Earth Operative Monitoring. Despite the extensive use and successful experience of geoportal developments, a number of studies that relate to the usability of such sites is relatively small, and some of these studies mainly deal with commercial cartographic products or services (e.g. Yahoo Maps or Google Maps). One of the interesting examples (Skarlatidou \& Haklay, 2006) showed the interests and expectations of users who visited pages of geoportals. In this study, the key emphasis was made only on the behavior of users without any experience in working with GIS.

Moreover, Hornbaek et al. (2002) primarily focused on the specific component of geoportal sites, namely an overview map. The authors analyzed the interactions of users with these maps. Other studies (Harrower \& Sheesley, 2005; You et al., 2007) made focuses on the navigation tools on the geoportal map data, as well as the methods of scaling. As shown in these papers, the design of the user interface has a significant impact on the usability of the platform. One of the significant drawbacks is that the analysis was conducted only on specific examples and functions ignoring the full coverage of all the functionality and opportunities of geoportals. Nivala et al. (2008) analyzed a number of commercial geoportal services on the basis of which a complex of applied works was conducted. According to the results of the study, 403 problems that arose when working with various platforms were identified. In addition to the identified drawbacks, several proposals were presented to address them and improve the ease of using services. The number of detected errors underscores the importance of analyzing geoportal Internet services. Kramers's research (2008) emphasized the fact that many users cannot cope with a large number of functional opportunities provided by modern geoportals. The reason for this lies in the development of such interfaces that are closer to professional GIS specialists but not to ordinary users. However, as practice shows, the user-oriented approach is an effective way to avoid the most common mistakes made by users when working with web-GIS.

A number of recent scientific articles (Resch \& Zimmer, 2013; Blake et al., 2017b; Gkonos et al., 2018) is devoted to open questions of the analysis of the convenience of using geoportal systems, the search for ways to improve user experience. Special attention is paid to visualization of cartographic data, as well as combined display of thematic 
layers and three-dimensional models (Hoarau, 2012; Hoarau et al., 2013; Horbiński \& Medyńska-Gulij, 2017), a numerical evaluation of the efficiency and convenience of graphical interfaces (Xin et al., 2012; Gkonos et al., 2018). Researchers agree that the problem solution of creating effective graphical geoportal interfaces is the initial formation of a design focused on a person, created to solve specific problems based on best practices and design patterns (Panchaud \& Hurni, 2018).

A set of qualitative and functional requirements for interfaces is traditionally presented to geoinformation systems inheriting key properties of wide-range software information systems and with the help of these requirements they interact with the surrounding world (Maguire \& Longley, 2005). In this specific area, the Application Programming Interface (API) and Graphical User Interface should be considered separately. The first class of interfaces provides the possibility of automatic or automated interaction with GIS including remote system management and data exchange. To maximize the effectiveness of these processes, specialized geodatabase formats and standards are used (GeoJSON, TopoJSON, KML).

They are deployed on the basis of such styles of interaction of components as REST, subsystems of Web API and web services functioning. The problem of developing reliable, easily modifiable applicative programming interfaces takes a special place in solving the problem of putting into operation the effective GIS. In this article we will dwell on the problem of creating modern web-based GIS: designing and developing stable, adaptive, intuitively understandable geoportal interfaces .

\section{Support points for creating geoportal interfaces}

Analysis of existing geoportal solutions and experience in designing and developing web-based GIS (Yamashkin, 2015) permits to form a list of support points and meaningful following these points allows to approach the creation of effective geoportal interfaces:

1. Orientation to the flexible process of developing interfaces of geoportal system the essence of this postulate is a permanent analysis of the strengths and weaknesses of a web-based GIS, its potential and external threats in a competitive Internet environment. In a dynamically developing Internet space the role of competent risk management which is necessary for sustainable development of a web project cannot be denied. Historically, the Waterfall Model of the life cycle of information systems is the first concept of software development described by Royce (1970). In this model, the process of creating software systems looks like a flow containing a certain clearly verified sequence of phases, and nowadays it most noticeably loses its relevance including the field of developing webbased GIS. It happens due to the fact that an attempt to initially think over all the functional and qualitative characteristics of the system is doomed to failure in the conditions of a polymorphic, constantly changing information world. Searching for an answer to this threat often goes into a flexible development characterized by a series of approaches to create software focused on iterative planning, risk management and dynamic requirements formation (Dingsøyr et al., 2010).

2. The need for cross-platform adaptive web-interfaces - the general introduction of smartphones and tablet computers into our lives resulted in a revolutionary change in the set of functional and qualitative requirements for graphical interfaces of web-based GIS. Capacitive sensors of modern devices give absolutely different possibilities for interaction with cartographic material allowing to control the processes of obtaining and changing geospatial content using gestures and specialized controllers. The presence of an encapsulated GNSS receiver allows to make a dynamic content selection relative to a user position or route, and the ability to make instantaneous photo and video leads to receiving a key for implementing the task of publishing urgent data from the first source. 
3. Orientation to the future - responding to the new urgent requirements, geoportal interfaces should be designed and developed as an investment in the future. Thus, the technologies of augmented and virtual reality which are currently at the stage of their dynamic development are able to change the appearance of modern GIS fundamentally in the near future, as it was previously done by the widespread introduction of mobile computers. At the same time, the Internet of Things (IoT), which is taking root in all spheres of life of our society has enormous prospects and promises a turning point in all spheres: tourism, agriculture, medicine, design and creation of smart energy-efficient homes and cities. In this context, geoportal systems become the key link in coordinating the relationship between a person and smart machines, as well as controlling machine-to-machine communication (M2M). Their cartographic interfaces should allow to provide effective monitoring and control over the functioning of smart devices as components of the Internet of Things.

4. Motivated refusal from geospatial content management systems - currently, there is a number of frameworks and geospatial content management systems capable of providing a basic framework and a structural frame for the deployment of geoportal applications and allowing to reduce the time for designing, developing and implementing geoportals. The prominent family representatives of such software products include ArcGIS (for Server produced by American company ESRI) or GeoMixer (produced by Engineering Technology Center "Scanex"). Generally, recognizing the constructive role of systems of this class, the authors of the article reasonably believe that it is possible to achieve maximum efficiency in the development of geoportals in the initial design based on a problem situation and not on the abilities of geospatial management content systems of third-party suppliers. This statement is based on two propositions: the universality of existing geoportal frameworks inevitably results in redundancy of software components and interfaces (Yamashkin, 2016); and their limitations, on the contrary, become a stumbling block for the development of their own geoportal which becomes a functional hostage to its structural frame. It should not be forgotten that ready-made third-party solutions cost relatively large amounts of money, and if their use to deploy complex geoportals from an economic point of view may be appropriate (due to time and cost savings for developers), then such cooperation may prove to be economically unprofitable when building web-based GIS of middle and small scale. Finally, geospatial content management systems of leading vendors are written by ordinary specialists, so their software and architectural implementations are not devoid of vulnerabilities that endanger the data published on the Internet and users of the system. The key danger is that hundreds of organizations use ready-made geoportal solutions, and if an attacker finds a vulnerability in one typical, often analysis-accessible solution, all organizations that use them will be in danger. With a motivated refusal from third-party systems for managing geospatial content, problems of a different kind arise based on the need to form their own cohesive project team to create a geoportal or to find a solution in the field of IT outsourcing. However, despite the need for greater effort, the result can be rather fruitful, and it can be expressed in high efficiency, fault tolerance, extensibility and modifiability of the solution obtained. Finally, the geoportal graphical interfaces constructed in this way will not be limited by the functionality provided by the suppliers of the ready-made geoportal frames but will be tooled for solving specific problems.

5. Using third-party libraries where necessary - the previous point does not at all mean a complete refusal from ready-made solutions, but only focuses on the danger that the use of geospatial content management systems entails the appearance of limitations in the functional and qualitative characteristics of the system among which security has 
an important role to play. A paradigm like a component-oriented programming that involve the reuse of independent modules of source code is currently at the height of its development having already proved its effectiveness in web technologies for a long time (Khitrin, 2017). Therefore, the use of external libraries of third-party suppliers that solve a task in the construction of geoportal systems, in particular their interfaces, should not be forbidden. This approach allows to save a significant amount of time and money resources due to the replacement of the need for self-implementation of some modules. This substitution takes its toll: having implemented a third-party software component into the system, the developer of the geoportal takes responsibility in that at any moment he/she will be obliged to modify this module under a certain problematic situation. One can give a specific example illustrating this statement. The Leaflet.js library created to organize the basic framework for the operation of dynamic electronic cards is often motivated as a third-party module that is being introduced into geoportal systems. This step can lead to saving many hours of work of competent programmers, because the implementation of such a fast fail-safe component is comparable in labor intensity to the development of a medium-sized geoportal as a whole. However, the undeniable advantages of this library are its high optimization, light weight and modifiability, and these positive sides entail a challenge: if it is necessary to extend the functionality to its problem area, it is necessary to be ready to independently expand the provided functionality.

6. Human-centeredness of the interface design process is an important strategy in which the needs, desires and limitations of the end-users of the geoportal system are given considerable attention at each stage of the development process (Gkonos et al., 2018). Geoportal and cartographic design can be analyzed on the basis of studying the user's behavior (measuring the time spent on the resource, building a map of page transitions, scrolling and moving the mouse cursor). This is a common method for studying visual search problems and it contains design guidelines for improving geoportal interfaces that have a fairly long history of development. Jenks (1973) was one of the first cartographers to experiment with eye movement techniques in cartographic design. Observing user's behavior can be applied to the design of interfaces where a deeper understanding of the cognitive processes of obtaining information is required. The behavior data show which interface elements are interesting to users and which ones are mainly used for problem solving. Cognitive mapping uses cognitive theories and methods for understanding, producing and reading maps and geo-applications. Montello (2002) explained that informative and cognitive processes in cartography include several aspects: perception, learning, memory, thinking, reasoning, problem solving and communication.

7. Orientation to problem solving and achieving goals, which involves a list of support points for creating effective geoportal interfaces. More recently, the overwhelming number of web systems in all their diversity and geoportals in particular have been designed to represent an effective result of the work done. Currently, the dominant part of attention is paid to the creation of information systems that solve specific problems and function to achieve certain goals. The above list of support points for the creation of effective geoportal interfaces is not exhaustive but it includes a basic set of justified rules without which the development of effective geoportal solutions is under threat. Engineering requirements is a process which consists in the formation of a well-grounded list of functional and quality queries for the created geoportal interfaces. It is expedient to implement based on the compliance of these provisions.

\section{Examples of different approaches for designing geoportal interfaces}

Let's now turn to the consideration of the solutions realized by the authors of the article taking into account the support points for creating effective geoportal interfaces 
and basic functional and qualitative requirements. The geoportal called "Natural and Cultural Heritage of Mordovia" (https://tourismportal.net/) was created for the purposes of visualization and dissemination of information on the multi-layer structure, the heritage of the cultural landscape of Mordovia. The key task of designing a geoportal is to disclose information about its natural, sociocultural and infrastructural potential of the region. The graphical interfaces of the geoportal are oriented to usability and characterized by the properties of intuitive understandability, adaptability, modifiability, reliability and security. The functioning of the geoportal is based on the spatial-temporal systematization and comparative analysis of large volumes of information in order to form an idea of harmonious interaction of nature and society in the form of a model of the national cultural landscape that provides coordination of the search and rational use of data on ethnogeographic space. The structure of the projected information resource reveals the tourist and recreational potential of the cultural landscape of Mordovia through the visualization of natural and cultural heritage (Figure 1). The multilayer structure of the cultural landscape is represented by two organizational contents: an electronic map and an encyclopedic block (Yamashkin, 2016).

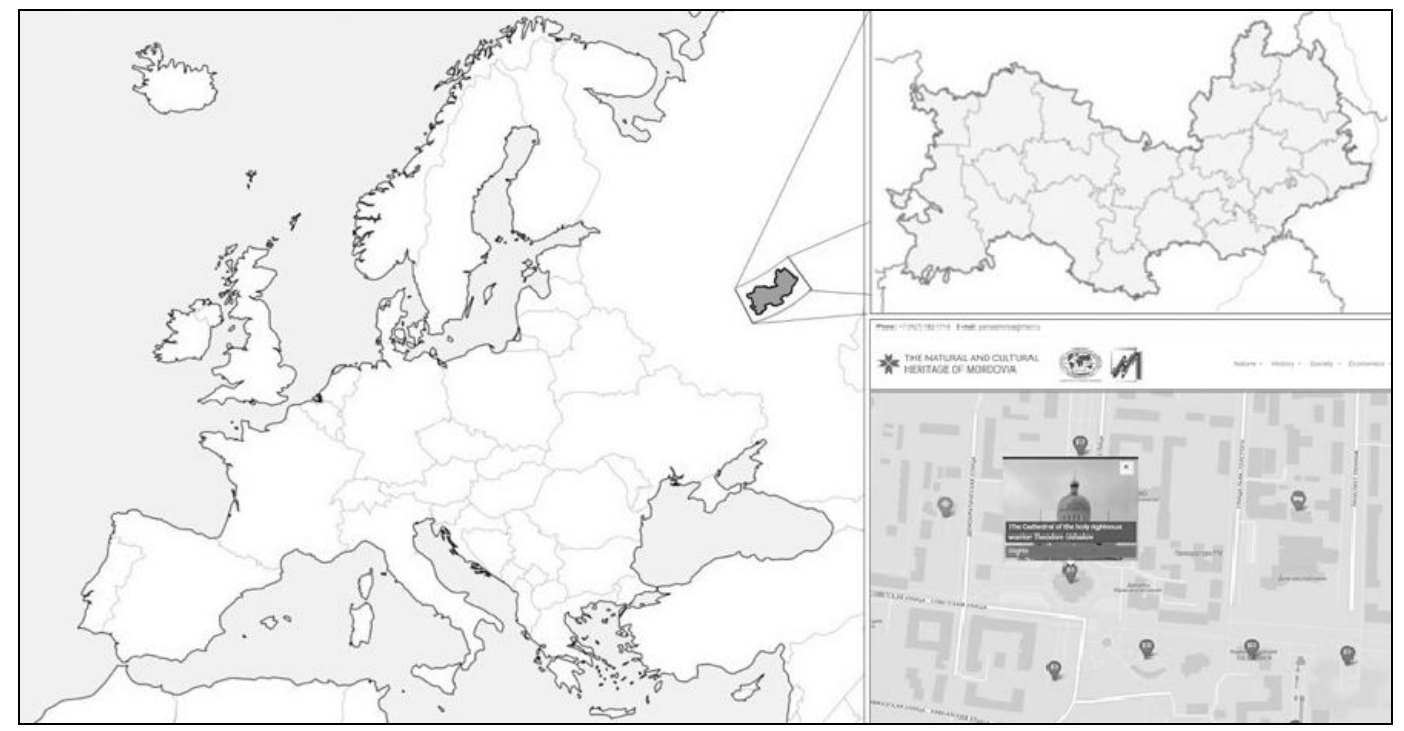

Figure 1. The geographical location map of the study area - Mordovia (Russian Federation)

Specially protected natural areas of federal and regional significance, rare plant and animal species are listed as elements of the natural heritage within the portal. Illustrating the cultural and historical potential in the structure of the geoportal is based on information on the region as part of the Finno-Ugric space, which has a significant material and spiritual heritage. The cultural and historical potential is realized in the description of ancient cultures, archeological monuments, the most ancient cities of Mordovia, existing urban and rural settlements, the ethnic composition of the population, religious sites, places where outstanding people lived, historical and cultural monuments of federal and regional significance. The social and economic block of the tourist and recreational potential is structured through analysis of the economy of the region: industry, agriculture, forestry, construction, transport and communications, support points of development (Popović et al., 2018). 
Another principle of building geoportal system is implemented in the project called Lifeshot.info. Its emphasis is to provide convenient cartographic interfaces to news information rather than to spatial objects as traditionally accepted. From the point of view of organizing control blocks, more attention is focused on the cartographic basis than in the previous example. Control components are designed in such a way as to provide an opportunity to obtain information about current news and events happening around the user. The approach to the conclusion of news information adopted in Lifeshot.info is unique and completely different from the solutions used by leading news vendors. The novelty and effectiveness of the result is due to the merger of the potential of geoportal systems and news resources. When developing a news geoportal, the property of adaptability of graphic interfaces is realized: it is convenient to receive information about surrounding events both from a desktop computer and from a mobile device. Currently, the prototype of the native geopolitical application Lifeshot.info is being developed for the Android operating system. Thereby, geoportal systems with well thought user interfaces can provide problem solutions from various problem areas whether it is disseminating information on the natural and cultural heritage of the region or solving the problem of efficient visualization of relevant news.

\section{MATERIALS AND METHODS}

\section{Functional and qualitative requirements for geoportal interfaces}

Recognizing the reasonability of orientation to the flexible process of developing interfaces for geoportal systems and the need for a dynamic permanent formation of the requirements for them, one can nevertheless list the functional and qualitative requirements that will be necessary when designing the vast majority of geoportal solutions. Formation of a set of requirements should be carried out based on the list of support points for creating effective geoportal interfaces given in the previous section of the article. Functional requirements cover regulations of the system describing its behavior and options for using. The main question: "What should the geoportal system do?". The list of basic requirements for graphical interfaces for web-based GIS of this category is shown below (Figure 2).

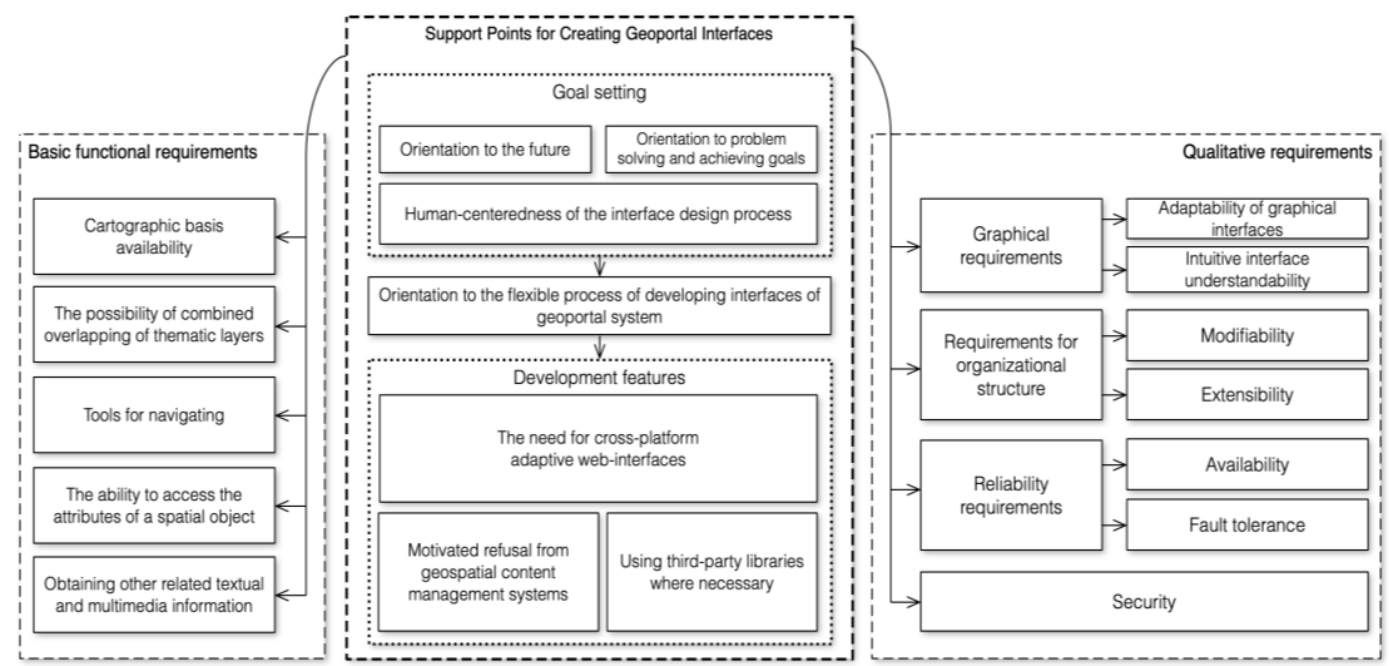

Figure 2. The support points for creating geoportal interfaces and the requirements they form

Cartographic basis availability is a requirement that allows to provide an intuitive visual reference of the spatial objects of geoportal to real world areas. Yandex Maps, 
Google Maps, Bing and other vendors, OpenStreetMap (OSM) road layers, space images of various satellites and resolutions can act as a basic framework. The specification of the present requirement can be the function of changing the cartographic basis by the user. The possibility of combined overlapping of thematic layers is a function of almost every geoportal solution, the choice of categories and parameters of spatial objects is a variant part here. Specification of using the indicated option can be very diverse and include the specification of the list of control elements of thematic layers, as well as scenarios for selecting the displayed objects. Tools for navigating the geospatial database including scaling the map and navigating through it with dynamic loading of objects and multicriteria search. In times of implementation of these functions it is important to rely on the possibility of input/output of information on various user devices: for example, on a smartphone, geoportal navigation tools will be more concise, some of them will be hidden in the departing menus but they can fully rely on the potential of touch control, rather than desktop interfaces. The ability to access the attributes of a spatial object is a requirement that aims to obtain detailed information about spatial objects. In particular, a detailed description of a section of the Earth can appear in a modular pop-up window and contain textual information and multimedia data. Object attributes are able to maximally expand a fixed, rigidly defined set of object nomenclature classes allowing to provide a variety of necessary information on an interesting element of the geospatial database. Obtaining other related textual and multimedia information that does not have a spatial reference. To achieve the tasks in various problematic situations, the geoportal system should often provide relevant information without regional reference. Contact information, encyclopedic materials, news feed, various data banks provide good examples. Focusing attention on geo-spatial cartographic materials, geoportals do not have to be limited only by them. If the need to implement functional queries is almost never in doubt, then executing many important qualitative (non-functional) queries often remains out of the engineering requirements. Nevertheless, the efficiency of the geoportal system directly depends on it. Qualitative requirements answer the question: "How should geoportal interfaces work?" It is necessary to mention separately the following list:

1. Graphical requirements determine the fact how graphical geoportal interfaces should look like. This area should be decomposed into the following blocks: adaptability of graphical interfaces and intuitive interface understandability.

2. Requirements for organizational structure divided into modifiability and extensibility indicate that the software implementation and design solutions of geoportal interfaces should provide quick and effective vertical (intensive) and horizontal (extensive) extension. Thus, cartographic interfaces should allow to connect new thematic layers easily, as well as reorient to solve new problems. From the point of view of implementation, graphic interfaces should function on the basis of fault-tolerant loosely coupled modules whose architecture allows to reuse the program code.

3. Reliability requirements including availability and fault tolerance describe the attributes of system quality characterized by the time of continuous operation of geoportal interfaces and the maximum allowed wait time. Components of cartographic geoportal interfaces must be repeatedly tested in order to minimize the probability of failure. It is important to remember that testing can never identify all the vulnerabilities of the system, but it should strive to make the fullest possible verification of the correspondence between the actual and expected behavior of the system on the final set of tests. Since geoportals belong to the class of distributed web systems and are accessed by a limited number of Internet users, it is important to ensure the stable functioning of the interfaces in conditions of powerful traffic flows. High-speed response ensures the speed and smoothness of interaction with geoportal interfaces. 
4. Security is an unquestionably important qualitative requirement for the interfaces of the geoportal system including a request for delineation of access, provision of work with private data and reduction of risks from external attacks.

The indicated list of requirements is not exhaustive, it can and should be extended when designing a specific problem-oriented GIS. However, it is strongly recommended to take it into account when designing your own effective geoportal solution.

\section{RESULTS AND DISCUSSION}

\section{Evaluation of the effectiveness of introduced geoportal interfaces}

In order to judge the effectiveness of the developed interfaces, it is advisable to collect statistical information on the process of using geoportal resource. Graphical interface is a face of the web-based system and the behavior of the visitors receiving information and navigating links depends directly on them.

To solve the task of behavior monitoring, an internal system for collecting statistics was developed which makes it possible to account the attendance of the resource and the behavioral indicators. The data was collected on the basis of the received information transmitted by the web client in the body of the HTTP request, in particular, the useragent (the line containing information about the software and hardware) and the client's IP address were analyzed. Here is a list of obtained indicators:

- Time spent on the geoportal is an important, informative and easily defined criterion reflecting the interest of visitors with the resource content. Users close uninformative pages a few seconds after opening them, they spend tens of minutes on interesting resources and hours on social networks every day. The higher this indicator is, the better. That is why the design of the portal, its functionality and content should be such that users spend maximum time on the resource.

- Geoportal visit depth shows how many pages the user browsed per visit. Going to one resource, the user can find all the necessary information on the first page. Users browse many pages on informative portals with good linking and this gives a good bonus when ranking such sites by search engines.

- Bounce rate - different search engines calculate the given indicator in diverse ways, but it is very important for all search engines. Often the indicator (percentage) of failures is the percentage of visitors who did not make the transitions to other pages of the site and left (refused further browsing) browsing not more than one of its pages. Reducing the value of this parameter can improve the design of the portal (special attention should be paid to optimizing navigation components) and increasing the value of the published content.

- Geoportal attendance is an important characteristic in itself, it is taken into account when ranking by search engines and indicates that the site is in demand among users. Together with other behavioral ranking factors, site traffic is an important criterion by which search engines evaluate web resources. The analysis of the effectiveness of changes is particularly informative. These variations are attracted by the modification of geoportal interfaces. Investigating the statistics of visits to "Natural and Cultural Heritage of Mordovia" geoportal, we divided the calculation of the indicators into two blocks: in the first case we determined the behavior indicators specific to the first cross-browser but nonadaptive version (functioning before September 1, 2017), in the second, to the updated adaptive design of the graphical interfaces described in this article. The results of the traffic behavior analysis are summarized in Table 1. The table shows that for the geoportal system with the second version of the interfaces, an increase in the relative share of a mobile traffic (visits from smartphones and tablets) comes at the expense of a decrease in the share of a desktop traffic. The objective process of widespread use of compact devices for browsing 
Internet systems also touched on the updated geoportal: adaptive interfaces became more accessible from the search results for mobile devices. The transition made it possible to reduce the bounce rate as well and increase the average time spent on the geoportal and the depth visit of its pages. Thus, the change of graphic interfaces did not pass without a trace: the use of new modern solutions contributed to increasing the degree of involvement of the World Wide Web users in the work with the geoportal.

Table 1. Quantitative traffic figures for the first and second versions of the interfaces of "Natural and Cultural Heritage of Mordovia" geoportal, as well as the values of their changes

\begin{tabular}{|c|c|c|c|c|c|}
\hline \multirow{2}{*}{$\begin{array}{c}\text { Version of } \\
\text { geoportal interfaces }\end{array}$} & \multirow{2}{*}{$\begin{array}{c}\text { Qualitative traffic } \\
\text { indicators }\end{array}$} & \multicolumn{4}{|c|}{ Type of device } \\
\hline & & $\mathrm{PC}$ & Smartphones & Tablets & TV sets \\
\hline \multirow{4}{*}{ First, cross-browser } & Unique visitors & $65.6 \%$ & $29.6 \%$ & $4.7 \%$ & $0.1 \%$ \\
\hline & Bounce rate & $13.1 \%$ & $18.7 \%$ & $13.7 \%$ & $1.5 \%$ \\
\hline & Average geoportal visit depth & 2.1 & 1.5 & 1.9 & 3.2 \\
\hline & Average time spent on & $3: 10$ & $1: 52$ & $2: 21$ & $3: 53$ \\
\hline \multirow{4}{*}{ Second, adaptive } & Unique visitors & $47.2 \%$ & $41.2 \%$ & $11.1 \%$ & $0.5 \%$ \\
\hline & Bounce rate & $12.3 \%$ & $14.6 \%$ & $11.1 \%$ & $0.5 \%$ \\
\hline & Average geoportal visit depth & 3.2 & 3.6 & 3.8 & 4.0 \\
\hline & Average time spent on the portal & $4: 16$ & $2: 47$ & $4: 31$ & $5: 58$ \\
\hline \multirow{4}{*}{$\begin{array}{l}\text { Change of } \\
\text { indicators } \\
\text { between } 1^{\text {st }} \\
\text { and } 2^{\text {nd }} \text { versions }\end{array}$} & Unique visitors & $\downarrow 18.4 \%$ & $\uparrow 11.6 \%$ & $\uparrow 6.4 \%$ & $\uparrow 0.4 \%$ \\
\hline & Bounce rate & $\downarrow 0.8$ & $\downarrow 4.1$ & $\downarrow 2.6$ & $\downarrow 1.0$ \\
\hline & Average geoportal visit depth & $\uparrow 1.1$ & $\uparrow 2.1$ & $\uparrow 1.9$ & $\uparrow 0.8$ \\
\hline & Average time spent on the portal & $\uparrow 0: 06$ & $\uparrow 0: 55$ & $\uparrow 2: 10$ & $\uparrow 2: 05$ \\
\hline
\end{tabular}

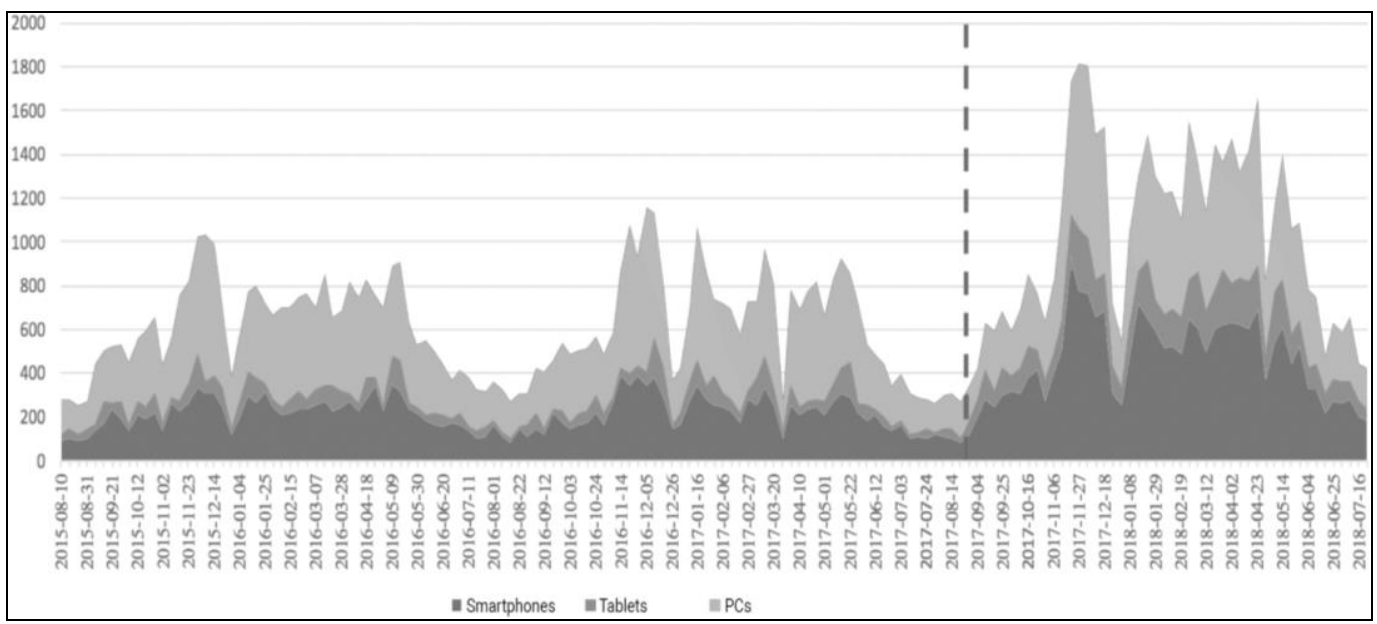

Figure 3. Schedule of changes in the attendance of the geoportal "Natural and Cultural Heritage of Mordovia". Note: the dashed line indicates the time of transition to new interfaces

It can be noticed that the positive change in the analyzed indicators is achieved not only through the modification of graphical interfaces, but also due to the development of published content and the increase in the recognition of the resource. This is true but having constructed a schedule of the dependence of geoportal attendance and values of behavioral indicators on time, it can be seen that the introduction of new adaptive interfaces indisputably contributed to the improvement of behavioral indicators (Figure 3). The decrease in the attendance of the geoportal in summer is due to the large percentage of vacations, in particular among educators and scientists who are the main consumers of 
geoportal content. The schedule shows that the introduction of new geoportal interfaces allowed to keep the trend of increasing the attendance of the resource in the autumnspring periods tolerating to growth the volumes of incoming traffic and its behavioral indicators, to save traffic from desktop client machines and to increase mobile one.

\section{CONCLUSION}

The conducted theoretical research and experience of practical development of geoportal systems allowed to draw the following conclusions' remarks:

1. Geoportals play an active role in ensuring the process of sustainable development of the global society by coordinating the search and rational use of natural resources, tourism, territorial and sectoral planning and property management, monitoring the social and environmental state of the region (Potic et al., 2017). In this case the effectiveness of geoportals strongly depends on the level of their users' graphical interfaces.

2. The analysis of existing geoportal solutions and experience in the design and development of geoportals made it possible to formulate a well-founded list of support points necessary for the creation of effective geoportal interfaces. It includes the following postulates: 1) orientation to the flexible process of developing interfaces of geoportal system; 2) the need for cross-platform adaptive Web-interfaces; 3) orientation to the future; 4) motivated refusal from geospatial content management systems; 5) using thirdparty libraries where necessary; 6) human-centeredness of the interface design process; and 7) orientation to problem solving and achieving goals.

3. The article contains a list of functional and qualitative requirements which are necessary when designing the vast majority of geoportal solutions. This list can be supplemented or decomposed in solving specific problems. The following functional requirements are identified: cartographic basis availability, the implementation of the possibility of combined overlapping of thematic layers, the availability of convenient navigation tools on the geospatial basis, access to attributive characteristics of spatial objects, as well as the possibility of obtaining other related textual and multimedia information. Adaptability of graphical interfaces for various devices, intuitive interface intelligibility, modifiability and extendibility, reliability and security are designated among the set of important qualitative queries.

4. As illustrative examples of different implementation of graphical user web interfaces, the article presents the case of "Natural and Cultural Heritage of Mordovia" geoportal and the Lifeshot.info news project. It is shown that well-thought out interfaces of geoportal systems can contribute to solving problems from various problem areas from the dissemination of information about the natural and cultural heritage to solving the problem of effective visualization of relevant news. The evaluation of the effectiveness of the implementation of adaptive geoportal interfaces was made which allows us to make a statement that the measures taken led to a positive growth of a mobile traffic on the project.

\section{Acknowledgments}

The research was supported by Ministry of Education, Science and Technological Development, Republic of Serbia (Grant III 47007).

\section{REFERENCES}

Blake, M., Majewicz, K., Mattke, R., \& Weessies, K. (2017a). A Spatial Collaboration: Building a Multi-Institution Geospatial Data Discovery Portal. Collaborative Librarianship, vol. 9, no. 3, p. 196-214.

Blake, M., Majewicz, K., Tickner, A., \& Lam, J. (2017b). Usability analysis of the Big Ten Academic Alliance Geoportal: Findings and recommendations for improvement of the user experience. Code4Lib Journal, vol. 38. 
Cegielska, K., Salata, T., Kudas, D., \& Szylar, M. (2018). Concept of Municipality Geoportal-Selected Legal and Administrative Issues. Geomatics and Environmental Engineering, vol. 12, no. 1, p. 45-57.

Dareshiri, S., Farnaghi, M., \& Sahelgozin, M. (2017). A recommender geoportal for geospatial resource discovery and recommendation. Journal of Spatial Science, p. 1-23.

Denzer, R., Argent, R., Schimak, G., \& Hřebíček, J. (2015). Environmental Software Systems. Infrastructures, Services and Applications. 11th IFIP WG 5.11 International Symposium, ISESS 2015, Melbourne, VIC, Australia, March 25-27, 2015, Proceedings. ISBN 978-3-319-15994-2

Dingsøyr, T., Dybå, T., \& Moe, N. (2010). Agile Software Development: Current Research and Future Directions. Springer, Berlin.

Fiedukowicz, A., Gasiorowski, J., Kowalski, P., Olszewski, R., \& Pillich-Kolipinska, A. (2012). The statistical geoportal and the "cartographic added value"- creation of the spatial knowledge infrastructure. Geodesy and Cartography, vol. 61, no. 1, p. 47-70.

Gachenko, A.S., Minayev, V.V., Mikhailov, A.A., Khmelnov, A.E., Fereferov, E.S., Fedorov, R.K., \& Vlasova, N.V. (2016). Information and Analytical System for Monitoring and Assessing the Anthropogenic Impact on the Coastal Zone Environment of Lake Baikal. Geography and Natural Resources, vol. 6, p. 174-178.

Giuliani, G., \& Peduzzi, P. (2011). The Preview Global Risk Data Platform: a geoportal to serve and share global data on risk to natural hazards. Natural Hazards and Earth System Science, vol. 11. no. 1, p. 53-66.

Gkonos, C., Iosifescu Enescu, I., \& Hurni, L. (2018). Spinning the wheel of design: evaluating geoportal Graphical User Interface adaptations in terms of human-centred design. International Journal of Cartography, p. 1-21.

Granell Canut, C., Miralles Tena, I., Rodríguez-Pupo, L. E., González-Pérez, A., Casteleyn, S., Busetto, L., \& Huerta Guijarro, J. (2017). Conceptual Architecture and Service-oriented Implementation of a Regional Geoportal for Rice Monitoring. ISPRS International Journal of Geo-Information, vol. 6, no. 7, p. 191.

Gunay, A., Akcay, O., \& Altan, M.O. (2014). Building a semantic based public transportation geoportal compliant with the INSPIRE transport network data theme. Earth Science Informatics, vol. 7, no.), p. 25-37.

Harrower, M., \& Sheesley, B. (2005). Designing better map interfaces: A framework for panning and zooming. Transactions in GIS, vol. 9, no. 2, p. 77-89.

Hoarau, C. (2012). Orthoimage or map visualization in use in geoportals, case study on the French geoportal. In Proceedings of AutoCarto2012 Conference.

Hoarau, C., Christophe, S., \& Mustiere, S. (2013). Mixing, blending, merging or scrambling topographic maps and orthoimagery in geovisualizations? In Proceedings of 26th International Cartographic Conference (ICC'13), Dresden, Germany.

Horbiński, T., Medyńska-Gulij, B. (2017). Geovisualisation as a process of creating complementary visualisations: static two-dimensional, surface three-dimensional, and interactive. Geodesy and Cartography, vol. 66, no. 1, p. 45-58.

Hornbaek, K., Bederson, B.B., \& Plaisant, C. (2002). Navigation patterns and usability of zoomable user interfaces with and without an overview. ACM Transactions on Computer-Human Interaction. vol. 9, p. 362-389.

Inspire Directive. (2007). Directive 2007/2/EC of the European Parliament and of the Council of 14 March 2007 establishing an Infrastructure for Spatial Information in the European Community (INSPIRE). Published in the official Journal on the 25th April, web: https://inspire.ec.europa.eu/about-inspire/563

Jenks, G.F. (1973). Visual integration in thematic mapping: Fact or fiction? International Yearbook of Cartography, vol. 13, p. 27-35.

Karabegovic, A., \& Ponjavic, M. (2012). Geoportal as decision support system with spatial data warehouse. In Computer Science and Information Systems (FedCSIS), 2012 Federated Conference on, pp. 915-918.

Khitrin, M.O. (2017). Comparing JavaScript Libraries for Web Mapping. Computer Technology, Management, Electronics, vol. 17, no. 3, p. 147-152.

Koshkarev, A.V., Antipov, A.N., Batuyev, A.R., Yermoshin, V.V., \& Karakin, V.P. (2008). Geo-portals as part of spatial data infrastructures: Russian Academy-supported resources and geoservices. Geography and Natural Resources, vol. 29, no. 1, p. 18-27.

Koszewski, K., Kowalski, P., Olszewski R., Włochyński L. (2018). Map Portal as a Tool to Share Information on Cultural Heritage Illustrated by the National Heritage Board Geoportal. In Advances in Digital Cultural Heritage: International Workshop, Funchal, Madeira, Portugal, 28.06.2017, Revised Selected Papers, Vol. 10754, p. 48-64.

Kramers, R.E. (2008). Interaction with Maps on the Internet - A User Centred Design Approach for The Atlas of Canada. The Cartographic Journal, vol. 45, no. 2, p. 98-107

Lombardo, V., Damiano, R., \& Lieto, A. (2015). Knowledge-based framework for the virtual communication of public art. In Innovative Mobile and Internet Services in Ubiquitous Computing (IMIS), 2015 th International Conference on, pp. 117-124.

Maguire, D.J., \& Longley, P.A. (2005). The emergence of geoportals and their role in spatial data infrastructures. Computers, Environment and Urban Systems, vol. 29, p. 3-14.

Mehdi, S.A., Ali, M., Nima, G., Zahra, R., Reyhaneh, S., \& Peyman, B. (2014). How to implement a governmental open source geoportal. Journal of Geographic Information System, vol. 6, no. 04, p. 275-285.

Montello, D.R. (2002). Cognitive map-design research in the twentieth century: Theoretical and empirical approaches. Cartography and Geographic Information Science, vol. 29, no. 3, p. 283-304.

Nivala, A.M., Brewster, S., \& Sarjakoski, L.T. (2008). Usability evaluation of web mapping sites. The Cartographic Journal, vol. 45, no. 2, p. 129-138. 
Panchaud, N. H., \& Hurni L. (2018). Integrating Cartographic Knowledge Within a Geoportal: Interactions and Feedback in the User Interface. Cartographic Perspectives, 89, p. 5-24.

Popović, D., Doljak, D., Kuzmanović, D., \& Pecelj, M. (2018). Geoecological evaluation of protected area for recreation and tourism planning - the evidence from the Bosnia and Herzegovina national park. Journal of the Geographical Institute "Jovan Cvijič" SASA, vol. 68, no. 1, p. 119-131.

Potić, I., Ćurčić, N., Potić, M., Radovanović, M., \& Tretiakova, T. (2017). Remote sensing role in environmental stress analysis: East Serbia wildfires case study (2007-2017). Journal of the Geographical Institute "Jovan Cvijić" SASA, vol. 67, no. 3, p. 249-264.

Reddy, G.P., Singh, S.K., Kumar, N., Mandal, C., Srivastava, R., Maji, A.K., \& Sarkar, D. (2018). Geospatial Technologies in Development of Soil Information System and Prototype GeoPortal. In Sustainable Management of Land Resources. ROUTLEDGE in association with GSE Research. pp. 411-442. DOI:10.9774/gleaf.9781315365565_17

Resch, B., \& Zimmer B. (2013). User experience design in professional map-based geo-portals. ISPRS International Journal of Geo-Information, vol. 2, no. 4, p. 1015-1037.

Royce, W. (1970). Managing the Development of Large Software Systems. Proceedings of IEEE WESCON, 26 (August), pp. 1-9.

Samakovlija, M., \& Bartoli, F. (2017). Open Geoportal lands to Europe: use cases and improvements from Geodata@ Polimi. In Free and Open Source Software for Geospatial Conference Proceedings. vol. 17, № 1, p. 11.

Sigala, M. (2012). Investigating the role and impact of geovisualisation and geocollaborative portals on collaborative elearning in tourism education. Journal of Hospitality, Leisure, Sport \& Tourism Education, 11, 50-66.

Skarlatidou, A., \& Haklay, M. (2006). Public Web Mapping: Preliminary Usability Evaluation. In Proceedings of GIS Research UK Conference, Nottingham, UK, 5-7 April.

Xin, H.E., Persson, H., \& Östman, A. (2012). Geoportal usability evaluation. International Journal, vol. 7, p. 88-106.

$\mathrm{Xu}, \mathrm{H}$., Shen B., \& Muste M. (2015). Geo-portal for sustainable culvert design and monitoring. In E-proceedings of the 36th IAHR World Congress 28 June - 3 July, 2015, The Hague, the Netherlands

Yakubaylik, O.E., Kadochnikov, A.A., \& Tokarev, A.V. (2014). Web application development based on technologies, resources and services of the Geoportal of the Institute of Computational Modelling SB RAS. Russian Digital Libraries Journal, vol. 17, no. 3.

Yamashkin, S., Radovanovic, M., Yamashkin, A., \& Vukovic, D. (2018a). Improving the Efficiency of the ERS Data Analysis Techniques by Taking into Account the Neighborhood Descriptors. Data, vol. 3, no. 2, p. 18.

Yamashkin, S., Radovanovic, M., Yamashkin, A., \& Vukovic, D. (2018b). Using ensemble systems to study natural processes. Journal of Hydroinformatics, vol. 20, no. 4, p. 753-765.

Yamashkin, S.A. (2015). Structure of the Regional Geoportal as a Tool for Publishing and Disseminating Geospatial Data. Scientific and Technical Volga Region Bulletin, vol. 6, p. 223-225.

Yamashkin, S.A. (2016). Methodical and Algorithmic Support of the Process of Analyzing the Lands Structure on the Database of Remote Sensing (Ph.D. Thesis Defense: Penza State University), p. 186.

Yermolaev, O.P., Mukharamova, S.S., Maltsev, K.A., Ivanov, M.A., Ermolaeva, P.O., Gayazov, A.I., \& Lisetskii, F.N. (2018). Geographic Information System and Geoportal "River basins of the European Russia". In IOP Conference Series: Earth and Environmental Science, vol. 107, №. 1, 012108.

You, M., Chen, C.W., Liu, H., \& Lin, H. (2007). A usability evaluation of web map zoom and pan functions. International Journal of Design, vol. 1, p. 15-25.

Zhu, X., She, B., Guo, W., Bao, S., \& Chen, D. (2015). Integrating Spatial Data Linkage and Analysis Services in a Geoportal for China Urban Research. Transactions in GIS, vol. 19, no. 1, p. 107-128.

*** Federal German Agency for Cartography and Geodesy. Retrieved from: https://www.geoportal.de/ [Accessed 24.09.2018].

*** Geo-informational register system of the Netherlands. Retrieved from: http://www.nationaalgeoregister.nl [Accessed 10 October 2018].

*** Geopolitical application of Russian Federation. Retrieved from: http://Lifeshot.info [Accessed 7 October 2018].

*** Geoportal of the Natural and Cultural Heritage of Mordovia. Retrieved from: https://tourismportal.net/ [Accessed 18.10.2018].

*** Geoportal of the Spatial Data Infrastructure of the Russian Federation. Retrievedfrom: http://nsdi.ru [Accessed 29.08 2018].

*** National Geoportal of France. Retrieved from: http://www.geoportail.gouv.fr [Accessed 10 October 2018].

*** National Land Survey Registry of Finland. Retrieved from: https://www.maanmittauslaitos.fi/ [Accessed 10.10.2018].

*** National Office of Geodesy and Cartography of Poland. Retrieved from: http://geoportal.gov.pl [Accessed 11.10. 2018].

*** Republic Geodetic Authority of Serbia. Retrieved from: http://www.geosrbija.rs [Accessed 25 September 2018].

*** Roscosmos Geoportal. Retrieved from: http://geoportal.ntsomz.ru [Accessed 10 October 2018].

*** Swedish Geodata Portal. Retrieved from: http://www.geodata.se [Accessed 5 October 2018].

*** The Federal Geoportal of Switzerland. Retrieved from: http://geo.admin.ch [Accessed 21 October 2018 ].

*** The US Geoplatform - Federal Geographic Data Committee. Retrieved from: http://www.geoplatform.gov/ [Accessed 12 October 2018].

Submitted:

10.11.2018
Revised:

25.01.2019
Accepted and published online 29.01.2019 